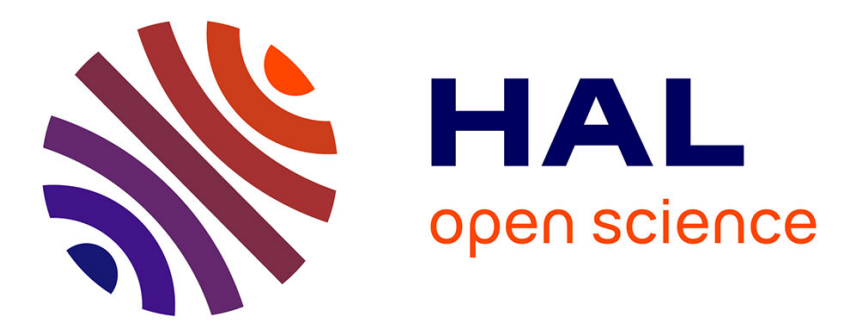

\title{
Health conditions and the risk of home injury in French adults: Results from a prospective study of the MAVIE cohort
}

Madelyn Rojas Castro, Marta Avalos, Benjamin Contrand, Marion Dupuy, Catherine Sztal-Kutas, Ludivine Orriols, Emmanuel Lagarde

\section{To cite this version:}

Madelyn Rojas Castro, Marta Avalos, Benjamin Contrand, Marion Dupuy, Catherine Sztal-Kutas, et al.. Health conditions and the risk of home injury in French adults: Results from a prospective study of the MAVIE cohort. 2020. hal-03085489

\section{HAL Id: hal-03085489 \\ https://hal.inria.fr/hal-03085489}

Preprint submitted on 21 Dec 2020

HAL is a multi-disciplinary open access archive for the deposit and dissemination of scientific research documents, whether they are published or not. The documents may come from teaching and research institutions in France or abroad, or from public or private research centers.
L'archive ouverte pluridisciplinaire HAL, est destinée au dépôt et à la diffusion de documents scientifiques de niveau recherche, publiés ou non, émanant des établissements d'enseignement et de recherche français ou étrangers, des laboratoires publics ou privés. 


\section{Health conditions and the risk of home injury in French adults: Results from a prospective study of the MAVIE cohort}

Rojas Castro (Madelyn Yiseth) ${ }^{1}$, madelyn-iseth.rojas-castro@u-bordeaux.fr, ORCID 00000001-7006-7946

Avalos (Marta) ${ }^{1,2}$, marta.avalos-fernandez@u-bordeaux.fr ORCID 0000-0002-5471-2615

Contrand (Benjamin) ${ }^{1}$, benjamin.contrand@u-bordeaux.fr

Dupuy (Marion) ${ }^{3}$, m.dupuy@calyxis.fr

Sztal-Kutas (Catherine) $)^{3}$, csk@calyxis.fr

Orriols (Ludivine) ${ }^{1}$, orriolsludi@ hotmail.com

Lagarde (Emmanuel)*1 , emmanuel.lagarde@u-bordeaux.fr, ORCID 0000-0001-8031-7400

${ }^{1}$ University of Bordeaux, Bordeaux Population Health Research Center, UMR U1219, INSERM, F-33000, Bordeaux, France.

${ }^{2}$ SISTM team Inria BSO, F-33405, Talence, France.

${ }^{3}$ Calyxis, centre of risk expertise, F- 79000, Niort, France.

*Corresponding author: emmanuel.lagarde@u-bordeaux.fr Tel/Fax: + (33) 557571537 


\section{ABSTRACT}

Background Home injury (HI) is a significant cause of mortality and morbidity in adults of all ages. Health conditions significantly impact $\mathrm{HI}$ among old adults, but little is known for other adults.

Study design Prospective cohort study

Objective: We assessed the associations between health-related factors and HI's risk in a French study, the MAVIE cohort.

Methods Poisson mixed models were fitted using health-related data information (diseases, treatments, and disabilities) at baseline and the number of injuries prospectively recorded during the follow-up, adjusting for significant socio-demographics and exposure to a range of home activities. Attributable fractions (AFs) were estimated based on RR estimations measured in the fully adjusted models.

Results A total of 6,146 dwelling adults aged 15 or more were followed up for 5.1 years on average. Vertigo or dizziness ( $R R=2.36,95 \%$ CI 1.06 to 5.01$)$ and sciatica or back pain $(\mathrm{RR}=1.49,95 \% \mathrm{CI} 1.08$ to 2.05$)$ were independently associated with an increased risk of HI. These two groups of conditions showed the most significant associations among people aged 15 to 49 , whereas musculoskeletal diseases other than rachialgias and arthropathies were the most significant health-related risk factor in people aged 50 and more. Sciatica or back pain represented the highest-burden of HIs in overall adults (8\%) and among people aged 15 to 49 $(12 \%)$.

Conclusion Our results suggest that adults with musculoskeletal disorders and vertigo or dizziness symptoms have a higher risk of HI, regardless of age.

Keywords Wounds and Injuries, Home Accident, Falls, Prospective Studies, Prevention 


\section{INTRODUCTION}

Home injuries (HIs) represent approximately one-third of the global burden of injuries ${ }^{123}$. In the EU-28, HIs caused an annual average of 85 thousand fatalities, 1.5 million hospital admissions, and 9 million emergencies between 2012 and $2014^{4}$. Home has been identified as the most prevalent location for injuries resulting in hospitalization and is second to roads as the location for fatal injuries 5 .

HIs affect people of all ages. However, among adults, HIs are more frequent in people aged 65 years or over. Falls are the principal mechanism of fatal and non-fatal $\mathrm{HIs}^{4}$.

Multiple studies have identified health-related factors associated with falls in the elderly, including: lack of strength gait and balance, mobility impairment ${ }^{6-8}$, back pain ${ }^{910}$, $\operatorname{arthropathies}^{811}$, dizziness and vertigo ${ }^{812}{ }^{13}$ obesity $^{14}$, diabetes ${ }^{7811}$, cardiovascular conditions $^{7811}$, chronic obstructive pulmonary disease ${ }^{11}$, urinary incontinence ${ }^{8}$, visual and hearing impairments ${ }^{7}$, cognition impairments caused by neurological conditions such as Parkinson's disease, Alzheimer's disease or other types of dementia ${ }^{6-8}$, and sleeping problems, anxiety or depression ${ }^{6-811}$. The presence of two or more concurrent conditions ${ }^{8}$ and certain medications, such as psychotropics, antidepressants, anxiolytics, sedatives or hypnotics ${ }^{15}$, opioids $^{16}$, cardiac medication, diuretics, anti-diabetic medication ${ }^{7}$, and polypharmacy ${ }^{17}$ are also associated with falls in the elderly.

Among young and middle-aged adults, understanding the impact of health risk factors on $\mathrm{HI}$ is poor $^{18}{ }^{19}$. Regarding the risk of occupational injuries, there is some evidence of the role of hearing impairments, neurotic illness, diabetes ${ }^{21}$, epilepsy, and sedating medication ${ }^{20}$. Conditions such as back pain, sleeping problems, anxiety, depression, cardiovascular diseases, and diabetes ${ }^{21}$ can also be frequent in young and middle-aged adults, which justifies evaluating their impact on adults of all ages. 
The purpose of this study was to assess associations of health-related factors on the risk of nonfatal $\mathrm{HI}$ in adults of all ages in a prospective cohort, the MAVIE cohort.

\section{METHODS}

\section{Study design and recruitment}

The MAVIE cohort is a web-based prospective cohort study conducted in France, with a longitudinal follow-up of Home, Leisure, and Sports Injuries (HLIs). All households in France and French overseas territories were eligible to participate. The recruitment process began in November 2014. The present study analyzed the data collected up to December 31, 2019. Cohort management was entirely online, including invitations, registration, and data collection. Participants were recruited through an email invitation sent to their insurees by three mutual insurance companies, press releases, social media, posters, and flyers. We asked potential participants to choose a household reference member in charge of completing a web-based questionnaire for the household. Consenting members of each household were asked to provide individual information. In an attempt to address the foreseeable underrepresentation of the elderly who may have difficulties using computers, caregivers were invited to represent and participate on behalf of one older person.

\section{Follow-up}

Every three months, household reference members received an email reminder to report any injury event to any consenting household members during the follow-up. If no event occurred, respondents were requested to report this. An invitation to report events was also included in the monthly cohort newsletter. Still, events could be reported at any time.

\section{Participant data and selection}


The inclusion criteria for participation in the MAVIE cohort were: i) residing in France; ii) being able to answer the questionnaires in French; iii) having access to and being able to use the Internet (at least the reference member). The baseline sample was defined as the participants aged 15 or over who answered at least one question of the individual inclusion questionnaire. We excluded those who lived in hospitals and retirement or long-term care institutions. We considered only participants who reported at least one feedback during follow-up and respondents to the daily schedule.

\section{Home Injuries}

This study focused on unintentional home injuries or its premises. We excluded all events involving illnesses or medical symptoms. We excluded events that occurred before or on the same date as the date of consent and those for which information about the type of medical care or the circumstances of occurrence was not reported. Finally, we excluded injuries that occurred during sleeping time, considered unlikely ${ }^{1}$.

Data included activity and location, mechanisms and type of medical care of the injury event. We defined HIs as severe when emergency care or hospital inpatient care was required.

\section{Individual characteristics}

Relative time distribution

Participants were asked to report their typical daily schedule in hours for each home location.

The average duration was also reported for domestic work, gardening, and do-it-yourself

(DIY) activities. Time spent on each activity was categorized as frequent (over the 75th percentile), occasional or null.

Socioeconomic, demographic characteristics, and alcohol consumption 
Gender, age, occupational status, education level, living situation, household incomes, and alcohol consumption were studied at baseline. Occupational status groups were unemployed, homemakers, and retirees and students and employees. Responses to education status were assigned to educational attainment levels by age groups. We considered a low level of education high school or vocational studies, or lower for participants aged 20 to 54, and primary studies or lower for other ages. Annual household incomes were assigned to classes according to the French population's percentiles reported in 2015 (Low: $\leq 30$ th percentile, Middle: 30 th-80th percentile, High: $\geq 80$ th percentile). The categories of the frequency of alcohol consumption were less than two times a week, and two or more times a week.

Health conditions and medications

At inclusion, participants were invited to report their history of diseases and treatments over the previous 12 months.

Medical conditions were grouped into the following clinically homogeneous categories: cardiovascular diseases, respiratory diseases, digestive diseases, genitourinary diseases, endocrine diseases, sciatica or back pain, arthropathies, other conditions of the musculoskeletal system, eye diseases, depression, anxiety, sleeping disorders (including treatment with antidepressants, anxiolytics or hypnotics), migraine or headache, vertigo or dizziness, chronic mental diseases (Parkinson's disease, Alzheimer's disease or other senile dementia, epilepsy, and antiepileptic medicines), and cancer. Participants were also asked to report whether they were suffering from impairments or disabilities related to vision, hearing, mental, intellectual, or psychological, and mobility.

We defined polypharmacy as a reported number of medications of 4 or more ${ }^{17}$, and comorbidity as the report of two or more diseases ${ }^{22}$ at any time in the previous 12 months. The history of injuries (excluding sports injuries) over the past 12 months was also reported. 


\section{Statistical analyses}

Data were analyzed using R version 3.6.1 (The R Foundation for Statistical Computing, Vienna, Austria)

We defined the follow-up period (FP) from the consent date to the latest date among the following: the latest news statement date, the questionnaires update date, the cohort exit date, the death date. We calculated the proportion of time spent awake at home (PTAH) as the proportion of hours on a weekday or weekend day when the person was neither away from home nor sleeping. We considered the time-at-risk as:

Time-at-risk $=\left(P T A H_{w} \times N o . F P w\right)+\left(P T A H_{w n} \times N o . F P w n\right)$, where $P T A H_{w}$ was the time spent awake at home regular weekday, $P T A H_{w n}$ on a regular weekend day, No. $F P_{w}$ the number of weekdays in the follow-up period and No. $F P_{w n}$ the number of weekend days. We calculated the proportion of time-at-risk as:

$\%$ Time-at risk $=($ Time-at-risk $/$ Follow-up duration $) \times 100 \%$.

\section{Risk factor analysis}

Poisson mixed models were used to fit the number of HIs during the estimated time at risk.

Random effects were included to take into account the cluster structure of data in households.

All models were fitted using the Template Model Builder R package ${ }^{23}$. Relative risks (RRs) were calculated conditionally upon the random effects, and the $95 \%$ confidence intervals were calculated using the profile method ${ }^{24}$. We adopted a complete case approach.

We fitted individual crude regression models to each health condition. Then, we conducted a two-step variable selection procedure. First, we adjusted each model by age, gender, and history of injuries in all models, and we selected the most important associations $\left(p_{a d j}<0.10\right)$. Second, we fitted the models to each health-related factor, adjusting for significant adjustment 
variables selected in the previous step. Finally, we selected the most important associations for the fully adjusted model (excluding comorbidity). Benjamini-Hochberg corrected p-values were computed $^{25}$. The same methodology was used to construct models stratified by two distinct age groups (15 to 49 years old and 50 years old or more).

The attributable fraction (AF) was estimated using the adjusted RR of the fully adjusted models, as suggested by Flegal and colleagues, $2006^{26}$.

\section{RESULTS}

Between November 2014 and December 2019, 11,420 adults registered in the MAVIE cohort and responded to baseline questionnaires. Among them, 9,429 were household reference members representing themselves and/or another household member. Sixty-six participants reported that living in a retirement institution, and 3,524 participants did not provide followup data. Another 1,684 participants did not provide their daily schedule (Figure 1). The sample size was 6,146 participants from 5,122 households.

The median follow-up was 4.0 years $(\mathrm{Q} 1=3.6, \mathrm{Q} 3=4.5)$. The overall follow-up duration was 4,800 persons-time. The loss to follow-up was $13 \%$.

Among the 6,146 individuals of the study, 244 left the cohort during the follow-up. Nineteen of them were reported by the reference member to have died, 16 from illness, and three of unknown causes. Thirty-one participants left the study due to changes in household composition. The remaining 191 participants did not report any reasons for leaving the study. Socioeconomic, demographic characteristics, and alcohol consumption levels were similar to those of the study sample and baseline sample (Table 1). However, dropout was more frequent among young adults, students, and employees, and among members of low-income households. 


\section{Baseline characteristics}

Socioeconomic, demographic characteristics, and alcohol consumption

Table 1 shows the socioeconomic, demographic characteristics, and alcohol consumption of the sample at baseline. Sample characteristics differed from those of the overall French population (INSEE Census, 2015). Participants aged 50 to 74 were overrepresented (62\% vs. $35 \%$ in the French population, 2015). Students and employees were underrepresented (49\% vs. 57\%). People with low education attainment level were underrepresented (8\% vs. 44\%). Finally, only $12 \%$ of household reference members reported an annual income lower than the 30 th percentile of French households.

The median proportion of time spent at home awake was $48 \%(\mathrm{Q} 1=36 \%, \mathrm{Q} 3=58 \%)$. Adults older than 50, unemployed, retirees, homemakers, and those who reported gardening, DIY, and domestic activities were those who spent the most time at home (Supplementary material $1)$.

\section{Health conditions, diseases, and medications}

Among the 6,146 participants, $67 \%$ reported at least one health condition (Figure 2). They were older, with a median age of 60 compared to 35 for those who did not report any health condition. Figure 2 shows the most frequently reported health conditions by age group. Almost half of the participants (48\%) reported more than one health condition. The most frequently reported conditions among adults aged 15 to 49 years were depression, anxiety, or sleeping disorders, and among adults aged 50 and more, cardiovascular diseases. Eight percent of participants reported at least one type of injury in the last 12 months.

\section{Home Injuries}


During follow-up, $12 \%$ of the participants reported at least one HI, of which 946 occurred while awake. Most of HIs were minor injuries, and only $28 \%$ required either hospitalization or emergency care. Falling was the main mechanism of HI (39\%), domestic and gardening activities (42\%), the most frequents activities, and the garden (25\%) the most frequent location (Supplementary Material 2).

\section{Health risk factor analysis}

Adjusting for the selected variables of block 1 (Table 2), vertigo or dizziness, sciatica or back pain, arthropathies, other musculoskeletal system diseases, depression, anxiety or sleeping disorders, and comorbidity were associated with an increased risk of $\mathrm{HI}$ in adults of all ages with a small or moderate effect (Block 2, Table 2). In the fully adjusted model (Table 3), vertigo or dizziness and sciatica or back pain remained associated with an increased risk of HI and with an $\mathrm{AF}$ of $1.9 \%$ and $8.1 \%$, respectively. The contribution of depression, anxiety, and sleeping disorders was also important $(\mathrm{AF}=5.5)$, but the association was weaker than the conditions named above $(\mathrm{RR}=1.28,95 \% \mathrm{CI} 0.96$ to 1.70$)$.

Results of the fully adjusted models were similar for participants aged 15 to 49 , but the effects of sciatica or back pain and vertigo or dizziness effects were higher than among adults of all ages (Table 4). The category of other musculoskeletal system diseases covered the only conditions significantly associated with the risk of $\mathrm{HI}$ among participants aged 50 or more (Table 4). All models converged, and their residuals were validated, discounting problems, such as over/underdispersion and zero inflation.

\section{DISCUSSION}

To our knowledge, we present here the first study to evaluate the association of health conditions with the risk of non-fatal HIs in adults of all ages. We followed up 6,146 cohort 
participants residing in French households, of whom 12\% suffered at least one HI over an average of 5.1 years. The same proportion was $14 \%$ among those who reported at least one health condition. Among the 21 health conditions reported at inclusion, we identified sciatica or back pain problems and vertigo or dizziness as the main risk factors, with an estimated AF of $8.1 \%$ and $1.9 \%$, respectively.

This unprecedented finding of substantially increased risk of HI among adults under 50 years old with sciatica or back pain $(R R=2.26)$ and vertigo or dizziness $(R R=4.59)$ is striking because of these high association measures, but also because of a substantial estimated AF (11.9\% and $3.2 \%$, respectively). For people over 50 years old, musculoskeletal diseases (other than rachialgia and arthropathies) are the only condition that remained significant in the fully adjusted model. These same factors associated with mobility emerged when we analyzed falls and shocks only, whereas this was not the case for other HIs. That suggests that most health conditions affecting the risk of $\mathrm{HI}$ are increasing the risk of falling. Other factors usually associated with injuries and falls, such as gender, age, vision and hearing impairments, polypharmacy, and alcohol consumption, did not appear to be associated with an increased risk of $\mathrm{HI}$ in this study.

Musculoskeletal conditions (including back pain) and sciatica are well-known risk factors for occupational injury, likely due to overexertion. Overexertion was reported only in the $18 \%$ of injuries of people suffering from musculoskeletal conditions. Consistent with previous findings, the effects of arthropathies $(\mathrm{RR}=1.37)$ and other musculoskeletal conditions $(\mathrm{RR}=1.57)$ were more relevant among adults over 50 years old ${ }^{811}$. In contrast to previous studies, back pain did not appear to be associated with an increased risk of $\mathrm{HI}$ in adults over $50^{9,10}$. One possible explanation is that older people may favor chronic conditions over problems such as back pain when self-reporting. We hypothesize that poor posture might 
affect housework performance, increasing general injury susceptibility. Decreased cognitive function due to chronic pain ${ }^{27}$ or opioid use ${ }^{16}$ might also raise HI risk.

Vertigo or dizziness increased the risk of HI among young adults, but not among those aged 50 or more. This group of symptoms may be related to vestibular migraine, benign paroxysmal positional vertigo, and Meniere's disease ${ }^{28}$, rather than age-related conditions such as Parkinson's disease, or cerebellum and oculomotor brain stem syndrome ${ }^{29}$. Other possible causes of vertigo, such as hypoglycemic episodes or postural hypotension, have been partially controlled for by adjusting for other conditions such as endocrine diseases and cardiovascular diseases.

We found a slightly increased risk of $\mathrm{HI}$ among those reporting depression, anxiety, or sleeping disorders. Consistently, Palmer and colleagues (2018) highlighted an increased risk of occupational injury among people with emotional conditions, and a moderate effect among sedatives consumers ${ }^{20}$. Another explanation might be the difficulties in assessing risks and a reduced motivation to correct them in people who have affective psychological disorders. Such an effect was observed for patients with Parkinson's disease ${ }^{30}$.

Unlike other studies ${ }^{2031}$, we found no association regarding age and disability. Because we could account for the time spent at home, our results confirm that exposure time is the main explanation ${ }^{132-34}$. A relevant self- perception of disability allows compensation for an increased risk of injury, enabling enhanced care in daily activities and avoiding risky tasks and domestic hazards. People with moderate conditions, more active in domestic work, and less aware of risks might be more exposed to hazards together they might insufficiently regulate their behavior. On the other hand, these effects may be mitigated by the beneficial impacts of domestic activities $^{35}$, for example, by improving executive functions ${ }^{36}$.

Lessons for prevention from our results include better awareness of risks at home for people with diseases related to the musculoskeletal system. Our results also highlight the preventive 
role of physicians when dealing with vulnerable people. However, HI risk related to the level of activities should not discourage leisure activities and help raise awareness and adaptation of the living environment to the risks by mapping foreseeable hazards.

\section{Limitations and Strengths}

Common limitations observed in volunteer-based cohorts and e-cohorts are low response rates, volunteer bias, loss of follow-up, and self-administered questionnaires, leading to selection biases and missing and selective answers. We made continuous efforts to address representativeness, loss to follow-up, and quality of information issues. However, young adults and people from low socioeconomic groups and levels of educational attainment were underrepresented. An overestimation of the prevalence and impact of some diseases is probable. The difficulty of diagnosing the conditions, the ability to recall, the willingness to report (mostly when communicated by reference members), physical and mental quality of life may also affect the report ${ }^{37}$. Besides, this study design does not allow us to disentangle the effects of health conditions and treatments. Moreover, information about disease severity, risk behaviors, and risk awareness was not available. Finally, we measured health conditions at a single time point; health changes were not assessed over time.

\section{Conclusion}

Despite these limitations, the MAVIE cohort is the injury observatory with the most detailed sociodemographic, contextual, and exposure information to study risk factors of HLIs in France. This information enabled us to control for potential confounders and account for exposure time, the latter being a rare opportunity.

\section{FOOTNOTES}


Acknowledgements: The authors express their thanks to all IETO team members for their help, especially Juan Naredo Turrado, Jeanne Duchesne, Li Lu and Marie-Odile Coste.

Contributors: All authors contributed to the study conception and design. Methodology: MR, MA and EL. Formal analysis: MR, Investigation: MR, MA, LO and EL. Writing original draft: MR Writing review \& editing: MA, BC, MD, CS, LO and EL. Supervision: EL, MA. Project administration: EL, CS and MD. Funding acquisition: EL, CS, and MD.

Funding: This study was financed jointly by the Institut de recherche en santé publique (IReSP) [CONV 067-00187II], the Agence nationale de sécurité du medicament et des produits de santé [conv 2014S029], the Université de Bordeaux and the Région Nouvelle Aquitaine as part of the Cassiopée project [conv 2014-1R30504 -00003101]. MR is the recipient of an INSERM/Région Nouvelle Aquitaine doctoral grant and is affiliated to the Digital Health program funded by France's Strategic Investment Programme. The MAVIE observatory is coordinated by the INSERM U1219-IETO team and Calyxis, pôle d'expertise $d u$ risque, with the support of the mutual insurance companies MAIF, MAAF, MACIF and Decathlon.

Competing interests: All authors have completed the ICMJE uniform disclosure form at www.icmje.org/coi_disclosure.pdf and declare: no support from any organization for the submitted work; no financial relationships with any organizations that might have an interest in the submitted work in the previous three years; no other relationships or activities that could appear to have influenced the submitted work.

Ethical approval: The French Data Protection Authority approved the protocol of this study. The study is declared to the CNIL under file number 912292. Identifying data were stored on servers located in a different location from those hosting the main database. Electronic informed consent was collected from all adult participants. participation of children was done under the responsibility and with the consent of a legal guardian. 
Data Sharing: Reasonable requests for patient level data should be made to the corresponding author and will be considered by. INSERM and Calyxis, Pôle d'expertise $d u$ risque responsible for any decision regarding the possible reuse of the data.

Patient and Public Involvement: Since inclusion, participants to the MAVIE cohort have received summaries of the main conclusions obtained and have at their disposal an application the MAVIE Lab that allows them to experiment with the results.

Transparency: EL (corresponding author) affirm that the manuscript is an honest, accurate and transparent account of the study being reported; that no important aspects of the study have been omitted; and that any discrepancies from the study as originally planned (and, if relevant, registered) have been explained.

\section{What is already known on the subject?}

- There is evidence that a large number of health conditions increase home injury risk in older adults.

- Musculoskeletal system diseases increase the risk of falls at home in older adults through weakness, loss of posture and balance.

- There is a lack of evidence on how health conditions affect the risk of home injury in younger adults.

\section{What this study adds?}

- Our results suggest a moderate to high effect of musculoskeletal system diseases and vertigo or dizziness symptoms over home injury risk regardless of age.

- Back pain or sciatica is the group of conditions with the highest attributable fraction of home injury risk among all adults and adults under 50 years old. 
medRxiv preprint doi: https://doi.org/10.1101/2020.10.10.20210435; this version posted October 11, 2020. The copyright holder for this preprint (which was not certified by peer review) is the author/funder, who has granted medRxiv a license to display the preprint in perpetuity.

\section{BIBLIOGRAPHY}

1 Kopjar B, Wickizer TM. Population-based Study of Unintentional Injuries in the Home. American Journal of Epidemiology 1996;144.https://academic.oup.com/aje/articleabstract/144/5/456/66488

2 Keall MD, Guria J, Howden-Chapman P, et al. Estimation of the social costs of home injury: A comparison with estimates for road injury. Accident Analysis and Prevention 2011;3. doi:10.1016/j.aap.2010.11.027

3 Keall MD, Ormandy D, Baker MG. Injuries associated with housing conditions in Europe: A burden of disease study based on 2004 injury data. Environmental Health 2011;98. doi:10.1186/1476-069X-10-98

4 Eurosafe. Injuries in the European Union. Summary of injury statistics for the years 20122014. EuroSafe 2016. www.eurosafe.eu.com

5 Keall MD, Baker M, Howden-Chapman P, et al. Association between the number of home injury hazards and home injury. Accident Analysis and Prevention 2008;40:887893. doi:10.1016/j.aap.2007.10.003

6 Laurence BD, Michel L. The Fall in Older Adults: Physical and Cognitive Problems. Current Aging Science 2017;10:185-200. doi:10.2174/1874609809666160630

7 Ambrose AF, Paul G, Hausdorff JM. Risk factors for falls among older adults: A review of the literature. Maturitas 2013;75:51-61. doi:10.1016/j.maturitas.2013.02.009

8 Deandrea S, Lucenteforte E, Bravi F, et al. Risk factors for falls in community-dwelling older people: A systematic review and meta-analysis. Epidemiology 2010;21:658-668. doi:10.1097/EDE.0b013e3181e89905

9 Marshall LM, Litwack-Harrison S, Makris UE, et al. A Prospective Study of Back Pain and Risk of Falls Among Older Community-dwelling Men. J Gerontol A Biol Sci Med Sci 2017;72:1264-1269. doi:10.1093/gerona/glw227

10 Marshall LM, Litwack-Harrison S, Makris UE, et al. A Prospective Study of Back Pain and Risk of Falls Among Older Community-dwelling Women. J Gerontol A Biol Sci Med Sci 2016;71:1177-1183. doi:10.1093/gerona/glv225

11 Dionyssiotis Y. Analyzing the problem of falls among older people. International Journal of General Medicine 2012;2012:805-813. doi:10.2147/IJGM.S32651

12 Choi NG, Choi BY, Dinitto DM, et al. Fall-related emergency department visits and hospitalizations among community-dwelling older adults: examination of health problems and injury characteristics. BMC Geriatrics 2019;19:1-10. doi:10.1186/s12877-019-13292

13 Alyono JC. Vertigo and Dizziness: Understanding and Managing Fall Risk. Otolaryngologic Clinics of North America 2018;51:725-740. doi:10.1016/j.otc.2018.03.003 
medRxiv preprint doi: https://doi.org/10.1101/2020.10.10.20210435; this version posted October 11, 2020. The copyright holder for this preprint (which was not certified by peer review) is the author/funder, who has granted medRxiv a license to display the preprint in perpetuity.

All rights reserved. No reuse allowed without permission.

14 Cho BY, Seo DC, Lin HC, et al. BMI and Central Obesity With Falls Among Community-Dwelling Older Adults. American Journal of Preventive Medicine 2018;54:e59-e66. doi:10.1016/j.amepre.2017.12.020

15 Seppala LJ, MAT Wermelink AB, de Vries MB, et al. Fall-Risk-Increasing Drugs: A Systematic Review and Meta-Analysis: II. Psychotropics. Journal of the American Medical Directors Association 2018;19:371.e11-371.e17. doi:10.1016/j.jamda.2017.12.098

16 Yoshikawa A, Ramirez G, Smith ML, et al. Opioid Use and the Risk of Falls, Fall Injuries and Fractures among Older Adults: A Systematic Review and Meta-Analysis. The Journals of Gerontology: Series A 2020;:1-7. doi:10.1093/gerona/glaa038

17 Zia A, Kamaruzzaman SB, Tan MP. Polypharmacy and falls in older people: Balancing evidence-based medicine against falls risk. Postgraduate Medicine 2015;127:330-337. doi:10.1080/00325481.2014.996112

18 Talbot LA, Musiol RJ, Witham EK, et al. Falls in young, middle-aged and older community dwelling adults: Perceived cause, environmental factors and injury. $B M C$ Public Health 2005;5:1-9. doi:10.1186/1471-2458-5-86

19 Stenbacka M, Jansson B, Leifman A, et al. Association between use of sedatives or hypnotics, alcohol consumption, or other risk factors and a single injurious fall or multiple injurious falls: A longitudinal general population study. Alcohol 2002;28:9-16. doi:10.1016/S0741-8329(02)00223-9

20 Palmer KT, Harris EC, Coggon D. Chronic health problems and risk of accidental injury in the workplace: A systematic literature review. Occup Environ Med 2008;65:757-764. doi:10.1136/oem.2007.037440

21 Ritchie H, Roser M. Causes of Death. Our World in Data Published Online First: 2020.https://ourworldindata.org/causes-of-death

22 Huntley AL, Johnson R, Purdy S, et al. Measures of Multimorbidity and Morbidity Burden for Use in Primary Care and Community. Annals of Family Medicine 2012;10:134-141. doi:10.1370/afm.1363.INTRODUCTION

23 Brooks ME, Kristensen K, Benthem KJ van, et al. glmmTMB Balances Speed and Flexibility Among Packages for Zero-inflated Generalized Linear Mixed Modeling. The $R$ Journal 2017;9:378-400.

24 Venzon DJ, Moolgavkar SH. A Method for Computing Profile-Likelihood-Based Confidence Intervals. Journal of the Royal Statistical Society: Series C (Applied Statistics) 1988;37:87-94. doi:10.2307/2347496

25 Benjamini Y, Hochberg Y. Controlling the False Discovery Rate: A Practical and Powerful Approach to Multiple Testing. Journal of the Royal Statistical Society Series A: Statistics in Society 1995;57:289-300. doi:10.2307/2346101

26 Flegal KM, Williamson DF, Graubard BI. Using adjusted relative risks to calculate attributable fractions. American Journal of Public Health 2006;96:398. doi:10.2105/AJPH.2005.079731 
medRxiv preprint doi: https://doi.org/10.1101/2020.10.10.20210435; this version posted October 11, 2020. The copyright holder for this preprint (which was not certified by peer review) is the author/funder, who has granted medRxiv a license to display the preprint in perpetuity.

All rights reserved. No reuse allowed without permission.

27 Moriarty O, McGuire B, Finn DP. The effect of pain on cognitive function: A review of clinical and preclinical research. Progress in Neurobiology 2011;93:385-404.

doi:10.1016/j.pneurobio.2011.01.002

28 Bisdorff A. Migraine and dizziness. Current Opinion in Neurology 2014;27:105-110. doi:10.1097/WCO.0000000000000061

29 Zarcone D, Corbetta S. Shared mechanisms of epilepsy, migraine and affective disorders. Neurological Sciences 2017;38:73-76. doi:10.1007/s10072-017-2902-0

30 Clemson L, Cumming RG, Roland M. Case-control study of hazards in the home and risk of falls and hip fractures. Age and Ageing 1996;25:97-101. doi:10.1093/ageing/25.2.97

31 Shi X, Wheeler KK, Shi J, et al. Increased risk of unintentional injuries in adults with disabilities: A systematic review and meta-analysis. Disability and Health Journal 2015;8:153-164. doi:10.1016/j.dhjo.2014.09.012

32 Ferrante P, Marinaccio A, Iavicoli S. Epidemiological risk analysis of home injuries in Italy (1999-2006). International Journal of Environmental Research and Public Health 2014;11:4402-4416. doi:10.3390/ijerph110404402

33 Mannocci A, de Waure C, Gualano MR, et al. Epidemiology of home injuries: a large observational study among adult mothers in Italy. Annali dell'Istituto Superiore di Sanità 2013;49:376-382. doi:10.4415/ANN_13_04_10

34 Farchi S, Rossi PG, Chini F, et al. Unintentional home injuries reported by an emergencybased surveillance system: Incidence, hospitalisation rate and mortality. Accident Analysis and Prevention 2006;38:843-853. doi:10.1016/j.aap.2006.02.009

35 Jiang $\mathrm{C}, \mathrm{Xu} \mathrm{Y}$. The association between mild cognitive impairment and doing housework. Aging and Mental Health 2014;18:212-216. doi:10.1080/13607863.2013.823376

36 Tsuchiya K, Mitsui S, Fukuyama R, et al. An acute bout of housework activities has beneficial effects on executive function. Neuropsychiatric Disease and Treatment 2018;14:61-72. doi:10.2147/NDT.S153813

37 Van den Akker M, van Steenkiste B, Krutwagen E, et al. Disease or no disease? Disagreement on diagnoses between self-reports and medical records of adult patients. European Journal of General Practice 2015;21:45-51. doi:10.3109/13814788.2014.907266

\section{FIGURES AND TABLES}

Figure 1 - Flowchart of study participants

Figure 2 - Self-reported health conditions at inclusion: Diseases reported during the 12 months prior to baseline, disabilities, and obesity at the time of inclusion by the analyzed dwelling-adults of the MAVIE cohort, stratified by age groups (at inclusion). Sample size $\mathrm{N}=$ 6,146 
medRxiv preprint doi: https://doi.org/10.1101/2020.10.10.20210435; this version posted October 11, 2020. The copyright holder for this preprint (which was not certified by peer review) is the author/funder, who has granted medRxiv a license to display the preprint in perpetuity.

All rights reserved. No reuse allowed without permission.

Table 1 - Description of the demographic, socioeconomic and other characteristics at inclusion time of MAVIE dwelling-adults: baseline and analyzed sample

\begin{tabular}{|c|c|c|c|c|}
\hline & \multicolumn{2}{|c|}{ Baseline Sample } & \multicolumn{2}{|c|}{ Analyzed Sample } \\
\hline & $n$ & $(\%)$ & $n$ & $(\%)$ \\
\hline All & 11,354 & & 6,146 & \\
\hline \multicolumn{5}{|l|}{ Gender } \\
\hline Male & 5,326 & (47) & 2,933 & $(48)$ \\
\hline Female & 6,028 & (53) & 3,213 & $(52)$ \\
\hline \multicolumn{5}{|l|}{ Age (years) } \\
\hline $15-29$ & 1,074 & (9) & 490 & $(8)$ \\
\hline $30-49$ & 3,251 & (29) & 1,611 & (26) \\
\hline $50-74$ & 6,542 & (58) & 3,823 & $(62)$ \\
\hline $75+$ & 487 & (4) & 222 & $(4)$ \\
\hline \multicolumn{5}{|l|}{ Employment Status } \\
\hline Students, Employees & 4,810 & $(52)$ & 2,998 & (49) \\
\hline Unemployed, retirees and homemakers & 4,395 & $(48)$ & 3,042 & $(51)$ \\
\hline missing & 2,149 & & 106 & \\
\hline \multicolumn{5}{|l|}{ Level of educational attainment by age ${ }^{a}$} \\
\hline Low & 823 & (9) & 474 & $(8)$ \\
\hline High & 8,434 & (91) & 5,658 & $(92)$ \\
\hline missing & 2,097 & & 14 & \\
\hline \multicolumn{5}{|l|}{ Living alone } \\
\hline No & 9,116 & (81) & 4,893 & $(80)$ \\
\hline Yes & 2,135 & (19) & 1,205 & $(20)$ \\
\hline missing & 103 & & & \\
\hline \multicolumn{5}{|l|}{ Frequency of alcohol consumption } \\
\hline Less of 2 times a week & 4,850 & $(60)$ & 3,422 & $(58)$ \\
\hline 2 times a week or more often & 3,247 & (40) & 2,496 & $(42)$ \\
\hline missing & 3,257 & & 228 & \\
\hline \multicolumn{5}{|l|}{ DIY/gardening } \\
\hline Never & 3,124 & (39) & 2,080 & (36) \\
\hline Occasional & 3,339 & (42) & 2,519 & $(43)$ \\
\hline Frequent & 1,573 & (20) & 1,228 & (21) \\
\hline missing & 3,318 & & 319 & \\
\hline
\end{tabular}


medRxiv preprint doi: https://doi.org/10.1101/2020.10.10.20210435; this version posted October 11, 2020. The copyright holder for this preprint (which was not certified by peer review) is the author/funder, who has granted medRxiv a license to display the preprint in perpetuity.

All rights reserved. No reuse allowed without permission.

\begin{tabular}{lrrrr}
\hline Domestic & & & & \\
Never & 1,928 & $(24)$ & 1,284 & $(22)$ \\
Occasional & 4,499 & $(56)$ & 3,306 & $(57)$ \\
Frequent & 1,561 & $(20)$ & 1,201 & $(21)$ \\
missing & 3,366 & & 321 & \\
\hline Household income level ${ }^{\text {b }}$ & $N=9,429$ & & $N=5,122$ & \\
Low & 1,176 & $(14)$ & 563 & $(12)$ \\
Middle & 3,320 & $(41)$ & 1,850 & $(40)$ \\
High & 3,655 & $(45)$ & 2,198 & $(48)$ \\
missing & 1,273 & & 511 & \\
\hline
\end{tabular}

a Level of educational attainment by age groups according to French population in 2015 (Low: < 50, High: $\geq$ P50\$).

b Household income according to percentiles of salaries of the French population in 2015 (Low: $\leq$ P30, Middle: P40 - P70, High: $\geq$ P80), frequencies calculated using the household as the unit, $N=$ number of households. 
Table 2- Individual factors associated with the incidence of HI, relative to the time at risk at home, in adults of the MAVIE cohort

\begin{tabular}{|c|c|c|c|c|c|c|}
\hline & \multicolumn{3}{|c|}{$\begin{array}{c}\text { Crude Models } \\
\underline{(n=6,146, H I=946)}\end{array}$} & \multicolumn{3}{|c|}{$\begin{array}{c}\text { Adjusted Models } \\
(n=4,498, H I=646)\end{array}$} \\
\hline & $n(\%)$ & RR $(95 \%$ CI $)$ & $p_{c}$ & $n(\%)$ & RR $(95 \% \mathrm{CI})$ & $p_{\mathrm{c}}$ \\
\hline Block 1: Adjustment variables & & & & & e model per variable) & \\
\hline Gender & 6,146 & & & 4,498 & & \\
\hline Female (vs. male) & $(52)$ & $0.98(0.84-1.15)$ & 0.908 & $(52)$ & $1.03(0.83-1.26)$ & 0.817 \\
\hline Age (years) & 6,146 & & & 4,498 & & \\
\hline $15-29$ (vs. 30-49) & $(8)$ & $0.94(0.64-1.36)$ & 0.850 & (9) & $1.25(0.79-1.96)$ & 0.313 \\
\hline $50-74$ & $(62)$ & $0.89(0.72-1.10)$ & - & $(61)$ & $0.84(0.64-1.11)$ & - \\
\hline $75+$ & (4) & $0.97(0.61-1.53)$ & - & (4) & $0.96(0.55-1.64)$ & - \\
\hline Level of educational attainment by age & 6,132 & & & 4,498 & & \\
\hline High (vs. Low) & $(92)$ & $1.75(1.24-2.53)$ & 0.007 & $(92)$ & $1.39(0.93-2.16)$ & 0.165 \\
\hline Household income level & 5,556 & & & 4,498 & & \\
\hline High (vs. Middle) & $(50)$ & $1.22(0.99-1.50)$ & 0.040 & $(49)$ & $1.37(1.07-1.76)$ & 0.003 \\
\hline Low & $(11)$ & $0.77(0.54-1.09)$ & - & $(12)$ & $0.62(0.41-0.93)$ & - \\
\hline Living alone & 6,098 & & & 4,498 & & \\
\hline Yes (vs. No) & $(20)$ & $1.29(1.03-1.59)$ & 0.046 & $(21)$ & $1.77(1.33-2.35)$ & 0.001 \\
\hline Frequency of alcohol consumption & 5,918 & & & 4,498 & & \\
\hline 2 or more times a week (vs. $<2$ times a week) & $(42)$ & $1.21(1.01-1.44)$ & 0.080 & $(41)$ & $1.20(0.96-1.49)$ & 0.165 \\
\hline DIY/gardening & 5,827 & & & 4,398 & & \\
\hline Occasional (vs. Never) & $(43)$ & $1.36(1.10-1.68)$ & 0.002 & (44) & $1.45(1.11-1.89)$ & 0.006 \\
\hline Frequent & $(21)$ & $1.59(1.26-2.02)$ & - & (22) & $1.69(1.24-2.30)$ & - \\
\hline
\end{tabular}




\begin{tabular}{|c|c|c|c|c|c|c|}
\hline Domestic & 5,791 & & & 4,391 & & \\
\hline Occasional (vs. Never) & $(57)$ & $1.27(1.02-1.59)$ & 0.189 & $(58)$ & - & - \\
\hline Frequent & $(21)$ & $1.18(0.91-1.53)$ & - & $(21)$ & - & - \\
\hline Employment status & 6,086 & & & 4,458 & & \\
\hline Unemployed, Homemakers or Retirees (vs. Students, Employees) & $(51)$ & $0.88(0.73-1.05)$ & 0.242 & $(50)$ & - & - \\
\hline History of previous injury & 5,301 & & & 4,498 & & \\
\hline Yes (vs. No) & (9) & $1.86(1.39-2.46)$ & $<0.001$ & $(9)$ & $1.58(1.15-2.16)$ & 0.008 \\
\hline Block 2: Health Variables & \multicolumn{3}{|c|}{ (one model per variable) } & \multicolumn{3}{|c|}{ (models adjusted for significant variables of the block 1) } \\
\hline Comorbidity & 5,919 & & & 4,414 & & \\
\hline$\geq 2$ diseases (vs. 1 disease or no disease) & $(50)$ & $1.57(1.32-1.87)$ & $<0.001$ & $(50)$ & $1.51(1.22-1.87)$ & $<0.001$ \\
\hline Vertigo or dizziness & 5,937 & & & 4,425 & & \\
\hline Yes (vs. No) & (1) & $2.75(1.55-4.78)$ & 0.002 & (1) & $3.12(1.55-6.07)$ & 0.002 \\
\hline Sciatica or back pain & 5,956 & & & 4,441 & & \\
\hline Yes (vs. No) & $(19)$ & $1.62(1.32-1.97)$ & $<0.001$ & (19) & $1.57(1.23-1.99)$ & $<0.001$ \\
\hline Arthropathies & 5,956 & & & 4,441 & & \\
\hline Yes (vs. No) & (13) & $1.38(1.10-1.74)$ & 0.002 & (13) & $1.37(1.03-1.82)$ & 0.034 \\
\hline Other musculoskeletal system diseases & 5,941 & & & 4,431 & & \\
\hline Yes (vs. No) & (19) & $1.46(1.19-1.78)$ & 0.002 & (19) & $1.44(1.12-1.83)$ & 0.006 \\
\hline Depression, anxiety or sleeping disorders & 5,055 & & & 3,819 & & \\
\hline Yes (vs. No) & $(19)$ & $1.44(1.15-1.80)$ & 0.006 & (19) & $1.41(1.07-1.86)$ & 0.020 \\
\hline Migraine or headache & 5,937 & & & 4,425 & & \\
\hline Yes (vs. No) & $(2)$ & $1.64(0.94-2.78)$ & 0.146 & (2) & - & - \\
\hline Chronic mental diseases & 5,183 & & & 3,904 & & \\
\hline Yes (vs. No) & (3) & $1.17(0.65-2.00)$ & 0.731 & (2) & - & - \\
\hline
\end{tabular}




\begin{tabular}{|c|c|c|c|c|c|c|}
\hline Digestive diseases & 6,009 & & & 4,475 & & \\
\hline Yes (vs. No) & (10) & $1.49(1.14-1.93)$ & 0.010 & (10) & $1.39(1.00-1.91)$ & 0.044 \\
\hline Cardiovascular diseases & 5,586 & & & 4,198 & & \\
\hline Yes (vs. No) & $(31)$ & $1.02(0.85-1.23)$ & 0.907 & $(30)$ & - & - \\
\hline Genitourinary system diseases & 6,009 & & & 4,476 & & \\
\hline Yes (vs. No) & (9) & $1.42(1.08-1.84)$ & 0.027 & (9) & - & - \\
\hline Eye diseases & 6,008 & & & 4,474 & & \\
\hline Yes (vs. No) & (7) & $1.31(0.96-1.76)$ & 0.148 & (7) & - & - \\
\hline Respiratory diseases & 5,946 & & & 4,439 & & \\
\hline Yes (vs. No) & (4) & $1.29(0.87-1.87)$ & 0.299 & (4) & - & - \\
\hline Cancer & 6,007 & & & 4,474 & & \\
\hline Yes (vs. No) & (4) & $1.27(0.82-1.91)$ & 0.395 & (4) & - & - \\
\hline Obesity & 5,998 & & & 4,465 & & \\
\hline Yes (vs. No) & (13) & $1.12(0.88-1.42)$ & 0.466 & $(13)$ & - & - \\
\hline Endocrine diseases & 5,482 & & & 4,132 & & \\
\hline Yes & $(10)$ & $0.97(0.72-1.30)$ & 0.907 & $(10)$ & - & - \\
\hline Hearing disability & 5,944 & & & 4,485 & & \\
\hline Yes (vs. No) & (7) & $1.26(0.93-1.69)$ & 0.228 & (7) & - & - \\
\hline Vision disability & 5,943 & & & 4,485 & & \\
\hline Yes (vs. No) & (12) & $1.14(0.88-1.48)$ & 0.425 & $(12)$ & - & - \\
\hline Mobility or physical disability & 5,946 & & & 4,485 & & \\
\hline Yes (vs. No) & (6) & $1.03(0.72-1.45)$ & 0.907 & (6) & - & - \\
\hline Mental, intellectual or psychological disability & 5,944 & & & 4,484 & & \\
\hline Yes & (1) & $0.98(0.42-2.09)$ & 0.954 & (1) & - & - \\
\hline
\end{tabular}




\section{Other disabilities}

Yes

Polypharmacy

Yes (vs. No)

Poisson mixed models per variable including offset term time spent at home during the follow-up and random effect in the variable

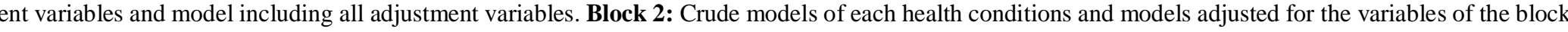

A

Benjamini \& Hochberg (1995) method.
5,941

(2) $\quad 1.31(0.76-2.18) \quad 0.425$

5,919

4,412

$(2)$


Table 3-Factors associated with the incidence of HI, relative to the time at risk at home, in adults of the MAVIE cohort (fully adjusted model)

Fully adjusted model*

$(n=3,842, H I=529)$

\begin{tabular}{lcccc}
\hline & $(\%)$ & RR (95\% CI) & $p$ & AF (\%) \\
\hline Vertigo or dizziness & $(1)$ & $2.36(1.06-5.01)$ & 0.029 & 1.9 \\
Yes (vs. No) & & & & \\
Sciatica or back pain & $(18)$ & $1.49(1.08-2.05)$ & 0.013 & 8.1 \\
$\begin{array}{l}\text { Yes (vs. No) } \\
\text { Arthropathies }\end{array}$ & $(12)$ & $1.10(0.75-1.58)$ & 0.629 & 1.5 \\
$\begin{array}{l}\text { Yes (vs. No) } \\
\text { Others musculoskeletal system diseases }\end{array}$ & $(18)$ & $1.04(0.75-1.42)$ & 0.830 & 0.8 \\
$\begin{array}{l}\text { Yes (vs. No) } \\
\text { Depression, anxiety or sleeping disorders }\end{array}$ & & & & \\
$\begin{array}{l}\text { Yes (vs. No) } \\
\text { Digestive diseases }\end{array}$ & $(19)$ & $1.28(0.96-1.70)$ & 0.084 & 5.5 \\
Yes (vs. No) & & & & \\
\hline Poisson model was adusted by the offset & & & \\
\hline
\end{tabular}

Poisson model was adjusted by the offset term time spent at home during the follow-up, random effect in the variable household, age, gender, history of previous injuries, household income level, living alone, and DIY and gardening . Abbreviations: $n=$ number of responders, $H I=$ number of home injuries, $\mathrm{RR}=$ relative risk, $\mathrm{CI}=$ confidence interval, $p=\mathrm{P}$ values, $\mathrm{AF}=$ attributable fraction. 
Table 4- Factors associated with the incidence of HI, relative to the time at risk at home, in adults of the MAVIE cohort by age group Adjusted models

Fully adjusted models

(\%)

Age 15-49

\section{Sciatica or back pain}

Yes (vs. No)

Vertigo or dizziness

Yes (vs. No)

Comorbidity

$\geq 2$ diseases (vs. 1 disease or not disease)

Age 50+

Others musculoskeletal

system diseases

Yes (vs. No)

RR $(95 \%$ C

$p_{c}$

(\%)

RR $(95 \%$ CI $)$

p $\mathbf{A F}(\%)$

$(n=1,804, H I=205)$

$2.40(1.49-3.91)<0.001$

(14)

$2.26(1.40-3.65)$

0.001

$4.95(1.76-13.75)$

0.002

$4.59(1.48-14.13)$

0.007

41)

$2.15(1.45-3.22) \quad<0.001$

$(n=2,915, H I=472)$

$(n=2,59, H I=468)$

Sciatica or back pain

Yes (vs. No)

11.9

Arthropathies

Yes (vs. No)

Comorbidity

$\geq 2$ diseases (vs. 1 disease or

no disease)

Poisson mixed models including offset term time spent at home during the follow-up and random effect in the variable household. Adjustment variables: Age 15-49 (gender, history of injuries), Age 50+ (gender, history of injuries, living alone, household income level, DIY/gardening, frequency of alcohol consumption). Abbreviations: $n=$ number of responders, $H I=$ number of home injuries, $\mathrm{RR}=$ relative risk, $\mathrm{CI}=$ confidence interval, $\mathrm{AF}=$ attributable fraction, $p_{c}=\mathrm{P}$-values ANOVA type II corrected using Benjamini \& Hochberg (1995) method, $p=\mathrm{P}-\mathrm{values}$ 
Baseline Adults

$$
N=11,420
$$

People living in retirement institutions

$N=66$

Baseline dwelling-adults

$N=11,354$

Lost to follow-up

$$
N=3,524
$$

Follow-up

$N=7,830$

No daily time schedule or invalid responses

$N=1,684$

Sample in the analysis

$N=6,146$ 


\section{Cardiovascular diseases}

$28 \%$

Other musculoskeletal system diseases

Sciatica and back pain

Depression, anxiety, sleeping disorders

Obesity Arthropathies

Visual disability

Digestive diseases Genitourinary system diseases

Endocrine diseases

Eye diseases

Hearing disability

Mobility and physical impairments

Respiratory diseases

Cancer

Migraine, headache and dizziness

Polypharmacy

Chronic mental illness

Other disabilities

Mental, intellectual and psychological disability

\begin{tabular}{|l|l|}
$18 \%$ \\
$18 \%$ \\
\hline
\end{tabular}

$16 \%$

$13 \%$

$12 \%$

$11 \%$

$9 \%$

$9 \%$

$9 \%$

$7 \%$

$7 \%$

$5 \%$

$4 \%$

$4 \%$

$3 \%$

$2 \%$

$2 \%$

$2 \%$

$1 \%$

0

500

1000

1500

Number of responders 